\title{
A study on the effects of marketing communication using integrated marketing communication
}

\author{
Solmaz Sellahvarzi ${ }^{a^{*}}$, Vahid Reza Mirabi ${ }^{\text {b }}$ and Mehdi Iran Nejad Parizi ${ }^{\mathrm{c}}$
}

\author{
C H R O N I C L E \\ Article history: \\ Received January 14, 2014 \\ Accepted 10 June 2014 \\ Available online \\ June 152014 \\ Keywords: \\ Relationship Marketing \\ Promotion Communication \\ Integrity \\ Integrated Marketing \\ Communication (IMC)
}

${ }^{a}$ Master's graduate in EMBA, Department of Management and Economy, Science and Research branch, Islamic Azad University, Tehran, Iran ${ }^{b}$ Professor, Faculty of Management, Islamic Azad University Central branch (Tehran), Iran

${ }^{b}$ Professor, full-time faculty member of Islamic Azad University, Science \& Research Branch, Tehran

\section{A B S T R A C T}

Integrated Marketing Communication (IMC) is one of the needed concepts in competitive edge. IMC is defined as a cross functional process for creating and nourishing profitable relationships with customers and other stakeholders by strategically controlling or impacting all messages sent to these groups. It ensures that all forms of communications and messages are carefully linked together. This study investigates the effectiveness of marketing communication in an Iranian automaker named Khodro using IMC system. The study tries to audit the rate of marketing relationship integrity and its outcome on organization performance. The study designs a questionnaire and distributes it among 384 randomly selected people who use this firm's services and Cronbach alpha has been calculated as 0.974. Hypotheses of this survey are exanimated by Pearson correlation test as well as pairwise t-student tests. The results show the effects of integrated marketing Communication on organization performance. In addition, there is a significant positive correlation relationship between integrated marketing communication with mission marketing, Cross functional Strategic Planning and Interactivity. Finally, there is a significant positive correlation relationship between dimensions of IMC.

\section{Introduction}

Recently marketers have turned away from mass marketing and they have concentrated more on integrated marketing. Meanwhile, advances in communications technology and the rapid growth of direct marketing may influence on the nature of marketing communications. Marketers who attempt to build relationships with different sectors and various markets have considered variety of methods and tools to increase sales by promoting and encouraging the development of policies. As a result, consumers have been exposed to different marketing communications. Marketing is a set of activities to create value exchange between business and customers (Shimp, 1993). It involves the exchange of information between producer and client (Pearson, 1996), it identifies essential customers' needs (Hersey \& Blanchard, 1988). Customers cannot differentiate between the sources of the messages as

*Corresponding author. Tel: +98912 3381457

E-mail addresses: solmaz sel@yahoo.com (S. Sellahvarzi) 
marketers. In terms of consumer advertising, messages from various data channels are merged and the boundaries often disappear. Conflicting messages from various data sources are the causes of the different images that people have from the company and the different products will be distorted. In most cases, firms cannot merge or integrate different communication channels, thereby establishing heterogeneous communication with customers.

Integrated Marketing Communications (IMC) systems can integrate all messages and pictures of the product in customer' mind (Kotler, 2003). It includes all routes that consignees read, see or even make sense of single message (Stephens et al., 1996). In today's competitive era not only the means of the access to clients but also the ways that clients can refer to organization should be integrated (Ried, Mike (2005). IMC means a cross-functional process for creating and nourishing profitable relationships with customers and other stakeholders by strategically controlling or impacting all messages sent to these groups and encouraging data-driven, purposeful dialogue with them (Duncan , 2002). It also means emphasize that the integration of marketing communication should not be understood as a simple uniformity of the message transmitted across different channels (Kitchen et al., 2004). Companies must measure the means of communication from the perspective of performance-cost with customer's awareness and motivation to purchase. They must able to choose appropriate mix of communication tools and to avoid doing repetitive, unequal and inadequate work. Consumers' perception of a company includes different messages that they receive including media advertising, pricing, packaging design, direct marketing, public relations, sales promotion, store displays and even the place of purchase for a product or service (Schultz \& Martin, 1979). Companies need "a 360-degree view" of the customer to fully understand all different ways that communication may influence customer behavior in their daily lives (Belch et al., 2008). The automotive industry is one of the largest industries in the world, where more than a hundred million people are employed in the industry. According to Drucker (1995), the automotive industry is mother of industries. Finding the relationship between the implementation of IMC and effectiveness in organizations of Iran Khodro is due to a large breadth of activities, having multiple products for different budgets, the huge number of customers, availability, importance of the industry and the relationship between other industries is the primary focus of this research. If the organization does not have a clear plan for communicating with their customers may face with confusion.

ICM is used to fix the problem, and to integrate the image of organization for customer. In this technique, the transferred image to an audience from marketing activities can be reviewed and efforts to integrate the activities surrounding the main objective are investigated. In this research, we will try using these techniques in an actual market analysis and offer possible suggestions. The purpose of this study is to evaluate the effectiveness of the implementation of integrated marketing communications by using IMC.

\section{The proposed study}

This study intends to evaluate the effectiveness of marketing communication by using ICM in Iran Khodro Co. The population of this study includes all customers, who purchase and use products of this company in city of Tehran/Iran. The sample size is calculated as follows,

$n=\frac{Z_{\alpha / 2} p(1-p)}{\varepsilon^{2}}$

where $N$ is the sample size, $p=1-q$ represents the probability, $z_{\alpha / 2}$ is CDF of normal distribution and finally $\varepsilon$ is the error term. For our study we assume $p=0.5, z_{\alpha / 2}=1.96$ and $e=0.05$, the number of sample size is calculated as $N=384$. The study uses a questionnaire consists of 35 questions. There are not several models, which represent the relationship between elements of IMC, as the main question of this research is the Evaluation of effectiveness of Marketing Communication by using IMC in 
Organization, model of this paper uses a model developed by Duncan (2002). Fig. 1 contains a model that present the relation between the elements of IMC.

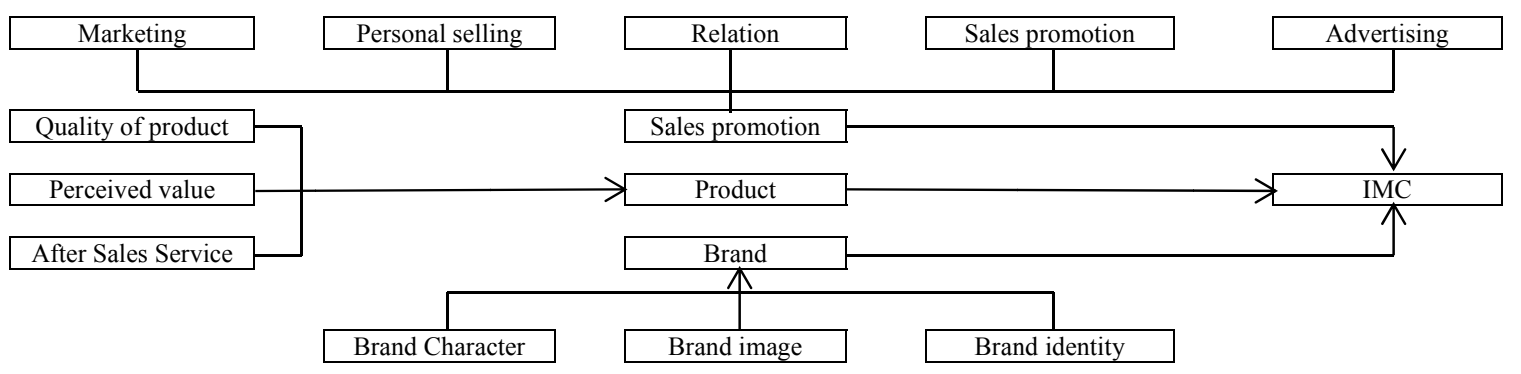

Fig. 1. The elements of IMC (Duncan, 2005)

Based on the framework of Fig. 1, the following five hypotheses are considered.

1-Iran Khodro Co has the required effectiveness on Marketing Communication with an integrated approach

2- Iran Khodro Co has the incumbent effectiveness on Marketing Communication influenced by product.

3- Iran Khodro Co has the incumbent effectiveness on Marketing Communication influenced by Brand.

4- Iran Khodro Co has the incumbent effectiveness on Marketing Communication influenced by Sales Promotion.

5- There is a significant relationship between elements of Marketing Communication.

The study uses structural equation modeling to examine the hypotheses of the survey and the implementation is executed on LISREL software package.

\section{Material and Methods}

This study is a descriptive and analytic applied research. The survey technique was implemented for collecting the necessary data from the respondents. The study has been developed for an automotive industry. To collect information of this study, a questionnaire, designed by the researcher, was used. With respect to 384 participants, reliability value of this questionnaire was calculated as 0.974 by Cronbach's Alpha Coefficient. Since this value is greater than 0.7 so reliability of questionnaire is demonstrated. Validity of the given questionnaire has been confirmed by means of comments from expert masters and the relevant specialists in this field.

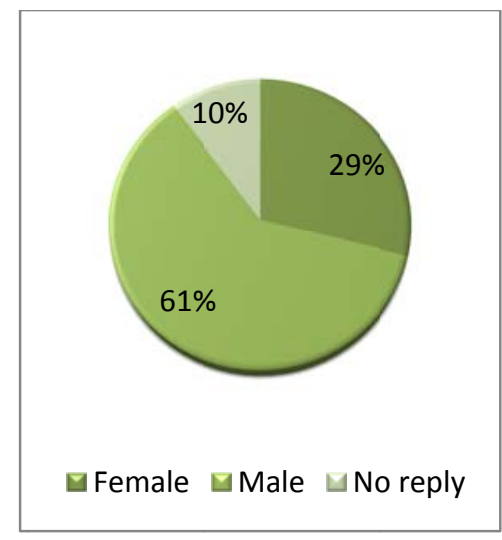

Gender

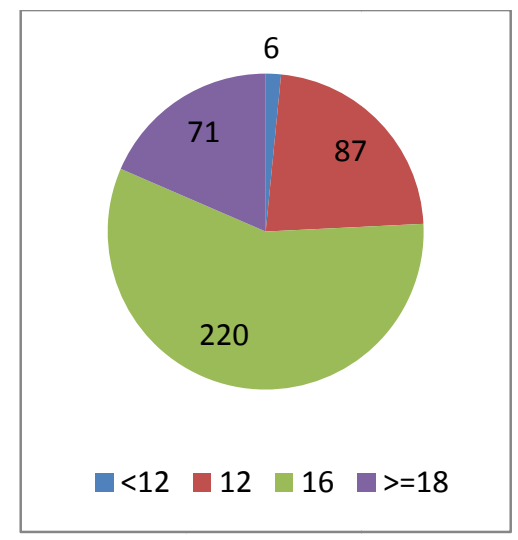

Years of education

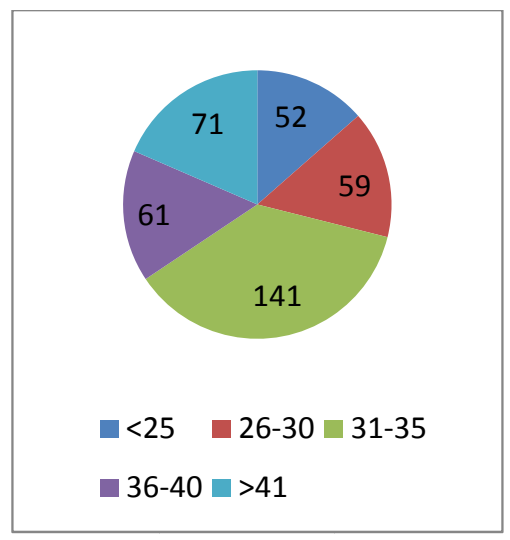

Age

Fig. 2. Personal characteristics of the participants 
As we can observe from the results of Fig. 2, most participants are middle aged male oriented who have had some university educations.

\section{Results}

\subsection{Analysis of Hypotheses}

To analyze the Evaluation of effectiveness of Marketing Communication by using Integrated Marketing Communication in Iran Khodro Co, the necessary data were gathered by researchers via designed questionnaire by them and then they were collected and reviewed and analyzed by means of Binomial Test, T- test and Friedman test.

\section{Table 1}

Existence of effectiveness in Marketing Communication of Iran Khodro

\begin{tabular}{ccccccc}
\hline & t-value & df & Sig. & Mean diff. & Min & Max \\
\hline $\mathrm{H}_{0}: \mu \leq 3$ & 2.029 & 180 & 0.58 & -0.10830 & -0.23416 & -0.0024 \\
\hline
\end{tabular}

As we can observe from the result of Table $1 \mu \leq 3$, Null Hypothesis is accepted, in terms of customers' perspective and there is not effectiveness of marketing communication in Iran Khodro Company.

Table 2

Sales promotion

\begin{tabular}{llccccc}
\hline & Group & Category & $\mathrm{N}$ & Observed prob. & Test prob. & Sig. \\
\hline $\mathrm{H}_{0}: \mathrm{P} \leq 0.6$ & First & $\leq 3$ & 98 & 0.3 & 0.6 & 0.89 \\
$\mathrm{H}_{1}: \mathrm{P}>0.6$ & Second & $>3$ & 286 & 0.7 & & \\
\hline & Total & & 384 & 1.0 & & \\
\hline
\end{tabular}

As we can observe from the result of Table 2, Alternative Hypothesis is accepted, from the view point of customers, Sells Promotion is effective in Iran Khodro Company.

Table 3

Dimensions of Sales Promotion

\begin{tabular}{|c|c|c|c|c|c|c|}
\hline & & Exact Sig & Test Prop & Observed Prop & $\mathrm{N}$ & Category \\
\hline \multirow{3}{*}{ Sales Promotion } & Group1 & $\leq 3$ & 158 & 0.6 & \multirow{3}{*}{0.6} & \multirow{3}{*}{$.499^{\mathrm{a}}$} \\
\hline & Group2 & $>3$ & 226 & 0.4 & & \\
\hline & Total & & 384 & 1 & & \\
\hline \multirow{3}{*}{ Public Relation } & Groupl & $\leq 3$ & 215 & 0.7 & \multirow{3}{*}{0.6} & \multirow{3}{*}{$0.79^{\mathrm{a}}$} \\
\hline & Group2 & $>3$ & 169 & 0.3 & & \\
\hline & Total & & 384 & 1 & & \\
\hline \multirow{3}{*}{ Advertising } & Group1 & $\leq 3$ & 254 & 0.3 & \multirow{3}{*}{0.6} & \multirow{3}{*}{$0.64^{\mathrm{a}}$} \\
\hline & Group2 & $>3$ & 130 & 0.7 & & \\
\hline & Total & & 384 & 1 & & \\
\hline \multirow{3}{*}{ Marketing } & Group1 & $\leq 3$ & 194 & 0.5 & \multirow{3}{*}{0.6} & \multirow{3}{*}{ a 0.68} \\
\hline & Group2 & $>3$ & 189 & 0.5 & & \\
\hline & Total & & 384 & 1 & & \\
\hline \multirow{3}{*}{ Personal Selling } & Group1 & $\leq 3$ & 208 & 0.4 & \multirow{3}{*}{0.6} & \multirow{3}{*}{${ }^{\mathrm{a}} 0.88$} \\
\hline & Group2 & $>3$ & 176 & 0.6 & & \\
\hline & Total & & 384 & 1 & & \\
\hline
\end{tabular}

As we can observe from the result of Table 3, by the means of Binomial Test in 2 dimensions Alternative Hypothesis are accepted, and in 3 dimensions Null Hypothesis are accepted.

Table 4

Product and 3 dimensions

\begin{tabular}{lllllll}
\hline Null Hypothesis: $\mathrm{H}_{0}: \mu \leq 3$ & $\mathrm{~T}$ & Df & Significant level & Diff of Mean & Min & Max \\
\hline Product & -3.288 & 180 & 0.029 & -0.18765 & -0.2675 & -0.654 \\
Perceived Value & -5.76 & 180 & 0.038 & 0.3876 & 0.5432 & 0.2543 \\
Quality & -0.68 & 180 & 0.54 & -03456 & -.1687 & 0.0965 \\
Sales Service & -1.876 & 180 & .49 & 0.9543 & 0.2345 & 0.354 \\
\hline
\end{tabular}


As we can observe from the result of Table 4, by the means of Test Value in 2 dimensions Alternative Hypothesis are accepted, and in 2 dimensions Null Hypothesis are accepted.

Table 5

Brand and 4 dimensions

\begin{tabular}{|c|c|c|c|c|c|c|}
\hline $\mathrm{H}_{0}: \mathrm{p} \leq 60 \%$ & & Exact Sig & Test Prop & Observed & $\mathrm{N}$ & Category \\
\hline \multirow{3}{*}{ Brand } & Group1 & $\leq 3$ & 186 & 0.6 & \multirow{3}{*}{0.6} & \multirow{3}{*}{$.456^{\mathrm{a}}$} \\
\hline & Group2 & $>3$ & 196 & 0.4 & & \\
\hline & Total & & 384 & 1 & & \\
\hline \multirow{3}{*}{ Image } & Group1 & $\leq 3$ & 297 & 0.4 & \multirow{3}{*}{0.6} & \multirow{3}{*}{0.00} \\
\hline & Group2 & $>3$ & 84 & 0.6 & & \\
\hline & Total & & 384 & 1 & & \\
\hline \multirow{3}{*}{ Identification } & Group1 & $\leq 3$ & 242 & 0.3 & \multirow{3}{*}{0.6} & \multirow{3}{*}{$0.543^{\mathrm{a}}$} \\
\hline & Group2 & $>3$ & 142 & 0.7 & & \\
\hline & Total & & 384 & 1 & & \\
\hline \multirow{3}{*}{ Character } & Group1 & $\leq 3$ & 235 & 0.5 & \multirow{3}{*}{0.6} & \multirow{3}{*}{$0.78^{\mathrm{a}}$} \\
\hline & Group2 & $>3$ & 149 & 0.5 & & \\
\hline & Total & & 384 & 1 & & \\
\hline
\end{tabular}

As we can observe from the result of Table 5, by the means of Binomial Test in 1 dimension Alternative Hypothesis is accepted, and in 3 dimensions Null Hypothesis is accepted.

Table 6

The results of ranking of IMC factors using Freedman test

\begin{tabular}{|c|c|c|c|c|c|c|c|}
\hline Factor & Mean rank & Factor & Mean rank & Factor & Mean rank & Factor & Mean rank \\
\hline Brand & 2.20 & Image & 2.49 & Quality & 2.29 & Advertising & 3.33 \\
\hline $\begin{array}{l}\text { Sales } \\
\text { promotion }\end{array}$ & 1.95 & Identification & 2.18 & $\begin{array}{l}\text { Perceived } \\
\text { value }\end{array}$ & 2.18 & $\begin{array}{l}\text { Sales } \\
\text { Promotion }\end{array}$ & 3.20 \\
\hline Product & 1.90 & Character & 1.59 & Sales service & 1.29 & $\begin{array}{l}\text { Public } \\
\text { Relation }\end{array}$ & 2.80 \\
\hline $\begin{array}{l}\text { Personal } \\
\text { selling }\end{array}$ & 2.37 & Marketing & 2.30 & & & & \\
\hline
\end{tabular}

As we can observe from the result of Table 6, by the means of Friedman test we can find the relative importance of each factor. This relationship was confirmed again in this study for the managers of Iran Khodro and the firm will be able to send an integrated message to their customers and community members.

\section{Conclusion}

In this paper, we have presented an investigation to learn more about Evaluation of effectiveness of Marketing Communication by using Integrated Marketing Communication in an automaker in Iran named Khodro. The study has distributed a questionnaire among some randomly selected people and using Spearman correlation ratios as well as Stepwise regression analysis, the study has determined that products and services dissatisfied consumers of Iran Khodro. Transmitted messages from firm are not coordinated and integrated with each other. According to the results we can say that the messages transmitted are not integrated, and all units of the affected product company engaged in communications, branding and sales promotion agencies did not act in accordance with the main objective and coherent picture of the organization. Organizations and companies will be successful if they do their best in the fastest possible time to the changing needs of humanity, and go beyond satisfying customers' needs. The customer compares consumer products in terms of price, quality and shape. The provided quality should be commensurate with the money spent by clients. The results of our study are consistent with findings of Pirsig in terms of product quality, perceived value of the product and after sales service. Today after sales services is one of the important factors that owners of 
factories and manufacturing should consider. If they pay attention to this service and do it correctly, it can increase customer satisfaction and convert them into permanent customers. The reality is that in today's turbulent world, having reliable Brand is a valuable capital.

\section{Acknowledgement}

The authors would like to thank the anonymous referees for constructive comments on earlier version of this paper.

\section{References}

Belch, G. E., Belch, M. A., Kerr, G. F., \& Powell, I. (2008). Advertising and Promotion: An Integrated Marketing Communications Perspective. McGraw-Hill.

Duncan, T. (2002). IMC: Using Advertising And Promotion To Build Brands Author: Tom Duncan, Publisher: McGraw-Hill Irwin Pages: 783.

Drucker, P. F. (1995). People and performance: The best of Peter Drucker on management. Routledge.

Hersey, P., \& Blanchard, K. H. (1993). Management of Organizational Behavior: Utilizing human resources . Prentice-Hall, Inc.

Kitchen, P. J., Brignell, J., Li, T., \& Jones, G. S. (2004). The emergence of IMC: a theoretical perspective. Journal of advertising research, 44(1), 19-30.

Kotler P. (2003). Marketing Management: Analysis, Planning, And Control. Prentice-Hall, Inc., Englewood Cliffs, New Jersey.

Moriarty, S. E. (1994). PR and IMC: the benefits of integration. Public Relations Quarterly, 39, 3844.

Pirsig, R. M. (1999). Zen and the art of motorcycle maintenance: An inquiry into values. Random House.

Reid, M. (2005). Performance auditing of integrated marketing communication (IMC) actions and outcomes. Journal of Advertising, 34(4), 41-54.

Pearson, S. (1996). Building brands directly: creating business value from customer relationships (Vol. 20, No. 6). Macmillan Business.

Schultz, D. E., \& Martin, D. G. (1979). Strategic advertising campaigns. Chicago: Crain Books. Shimp, T. A. (1993). Promotion management \& marketing communications.

Stephens, D. L., Hill, R. P., \& Bergman, K. (1996). Enhancing the consumer-product relationship: Lessons from the QVC home shopping channel. Journal of business research, 37(3), 193-200. 